\title{
A combined approach for colorectal management: worth for performing?
}

\author{
Viroj Wiwanitkit
}

Accepted: 8 January 2010 /Published online: 2 February 2010

(C) Springer-Verlag 2010

\section{Dear Editor:}

I read the recent publication "Laparoscopic correction of enterocele associated to stapled transanal rectal resection for obstructed defecation syndrome" by Carriero et al. (Int J Colorectal Dis 2010, in press) with great interest. Carierro et al. concluded that "The combination of STARR and laparoscopy provides a safe and effective method to treat ODS caused by rectal internal prolapse and/or rectocele combined with enterocele." Indeed, the combination of several manipulations usually brings higher risk than separated procedure in different time. The combo approach might reduce the time and preserve the surgical room for other cases; however, this means the patient has to expose to a longer and more complicated process. In surgery, "more steps" means more chance to get complication or increased risk. Also, more medical personnel are needed for the two approaches at the same time. Carriero et al. reported their impressive success, but there is no comparison to any other alternative. Whether their attempt to perform a complex procedure is clinically useful and worth doing or not is still a query to be answered.

Conflict of interest None.

V. Wiwanitkit $(\bowtie)$

Wiwanitkit House,

Bangkhae,

Bangkok, Thailand 10160

e-mail: wviroj@yahoo.com 